\title{
High seroprevalence of echinococossis, schistosomiasis and toxoplasmosis among the populations in Babati and Monduli districts, Tanzania
}

Mohammad Behram Khan', Parthasarathy Sonaimuthu', Yee Ling Lau ${ }^{1 *}$, Hesham M Al-Mekhlafi ${ }^{1}$, Rohela Mahmud', Nicholas Kavana², Ayub Kassuku ${ }^{2}$ and Christopher Kasanga ${ }^{2}$

\begin{abstract}
Background: The neglected tropical diseases, echinococcosis, schistosomiasis and toxoplasmosis are all globally widespread zoonotic diseases with potentially harmful consequences. There is very limited data available on the prevalence of these infections, except for schistosmiasis, in underdeveloped countries. This study aimed to determine the seroprevalence of Echinococcus multilocularis, Schistosoma mansoni, and Toxoplasma gondii antibodies in populations from the Monduli and Babati districts in Tanzania.

Methods: A total of 345 blood samples were collected from 160 and 185 randomly selected households from Babati and Monduli districts, Tanzania between February and May of 2012 and analyzed them using the enzyme linked immunosorbent assay. The antibodies were determined using the NovaLisa ${ }^{\circledR}$ Toxoplasma gondii IgG, NovaLisa ${ }^{\oplus}$ Schistosoma Mansoni IgG, NovaLisa ${ }^{\circledR}$ Echinococcus IgG and NovaLisa ${ }^{\circledast}$ Toxoplasma gondii IgM kits (Novatec, Germany).

Results: The seropositivity estimated for E. multilocularis, S. mansoni, and T. gondii lgG was $11.3 \%$ (95\% confidence interval (Cl): 7.96 - 14.6), 51.3\% (95\% Cl: 46.0 - 56.5), and 57.68\% (95\% Cl: 52.5 - 62.9), respectively. The seropositivity for T. gondii IgM was 11.3\% (95\% Cl: 7.96 - 14.6). Living in the Monduli district was found to be the main risk factor for $\lg$ G seropositivity for both schistosomiasis $(\mathrm{OR}=1.94 ; 95 \% \mathrm{Cl}: 1.23-3.08 ; \mathrm{p}=0.005)$ and toxoplasmosis $(\mathrm{OR}=2.09$; 95\% Cl: $1.31-3.33 ; p=0.002$ ).
\end{abstract}

Conclusions: These results suggest that restricting disease transmission, implementing control measures, and introducing training projects to increase public awareness are imperative, particularly for the Monduli district.

Keywords: Echinococcosis, Schistosomiasis, Toxoplasmosis, Zoonosis, Seroprevalence, Tanzania

\section{Background}

Parasitic infections are common in developing countries due to poor sanitation and inadequate personal hygiene. Undiagnosed and untreated parasitic infections can have severe consequences. Furthermore, many parasitic infections can persist for decades and result in significant morbidity and mortality. Diseases such as echinococcosis, schistosomiasis, and toxoplasmosis are globally widespread,

\footnotetext{
* Correspondence: lauyeeling@um.edu.my

'Department of Parasitology, Faculty of Medicine, University of Malaya, Kuala Lumpur, Malaysia

Full list of author information is available at the end of the article
}

and except for schistosomiasis there is little data on the prevalence in most developing countries, including Tanzania.

Echinococcosis is a zoonotic disease caused by metacestodes of Echinococcus granulosus, E. multilocularis, E. vogeli, and $E$.oligarthrus [1,2]. The larvae invade through the intestines and establish in distinct organs of the body; the liver is the most common organ affected, followed by the brain and muscles [3]. Transmission of Echinococcus relies on carnivores feeding on infected herbivores, thus a human infection is usually a dead end for the parasite, as it does not result in further transmission. In humans 
infected with Echinococcus, 60\% remain asymptomatic. Infection is confirmed by serological examination, because infected humans do not discharge Echinococcus eggs $[2,4]$. The two most medically relevant species, E. granulosus and E. multicularis, cause human cystic echnicoccosis (CE) and alveolar echinococcosis, respectively. CE contributes to more than $95 \%$ of the 2-3 million cases reported worldwide and 600,000 disability adjusted life years, while human alveolar echinococcosis gives rise to 0.3 - 0.5 million reported cases worldwide [5]. CE due to E. granulosus occurs on a global scale and is endemic in the Meditarranean, Central Asia, Northern and Eastern Africa, Australia, and South America [6,7]. The genetically similar E. multicularis causes alveolar echinococcosis in the northern hemisphere, specifically in China, Russia, Europe, and North America [8]. The existing data on CE in Africa is insufficient and out of date; therefore a complete picture of the epidemiological situation cannot be achieved.

Schistosomiasis, or bilharzia, caused by flukes of the genus Schistosoma, is one of the most common neglected tropical diseases. This parasite infects approximately 240 million people in 74 countries worldwide [9]. More than $90 \%$ of these cases are reported in Sub-Saharan Africa, where they have reported 200,000 deaths per year [10]. According to the World Health Organization in 2006, schistosomiasis and soil-transmitted helminthiasis contributes to more than $40 \%$ of all the tropical diseases, not including malaria. Furthermore, health statistics report that fewer than $5 \%$ of infected individuals are receiving praziquantel, an affordable anti-helminthic drug [11].

Toxoplasma gondii is an Apicomplexa parasite that infects a majority of bird and mammal species; however, felines are the only host that excretes the oocyst. Humans can become integrated into the life cycle of the parasite as an intermediate host either congenitally or post-natally by ingesting contaminated food or water, or an infected tissue cyst [12-15]. Congenitally infected individuals may experience neurological and vision defects as a result of infection. In post-natally infected immunocompromised patients $T$. gondii can cause chronic infections with symptoms such as retinochoroiditis, encephalitis, myocarditis, and hepatitis $[16,17]$. In immunocompetent patients, post-natal infections are usually asymptomatic, however, there can be exceptions that result in severe systemic illness. Globally, more than 2 billion people have been infected with this parasite [18]. Interestingly, the prevalence of $T$. gondii infection varies geographically as $6.7 \%$ of the Korean population is infected [19], $12.3 \%$ of the Chinese [20], $23.9 \%$ of the Nigerian [21], 46\% of the Tanzanian [22] and $47 \%$ of the population in the underdeveloped areas of France [23].

Echinococcosis, schistosomiasis, and toxoplasmosis pose a serious public health issue worldwide because there are no commercially available vaccines and currently, treatment depends on chemical drugs [24-26]. The objective of the present study was to investigate the E. multilocularis, $S$. mansoni, and T. gondii seroprevalence in the populations of the Babati and Monduli districts. The results provide a foundation to execute control strategies against these diseases in this province and elsewhere.

\section{Methods}

\section{Study area (Babati district)}

Babati district is a district of Manyara Region of Tanzania, East Africa. The administrative capital of the district is Babati town, $172 \mathrm{~km}$ south of Arusha. The district covers an area of $6,069 \mathrm{~km}^{2}$, a large proportion (640 sq km) of which is covered by the water bodies of Lake Babati, Lake Burunge and Lake Manyara. The district is bordered to the north by Arusha Region, to the southeast by Simanjiro District, to the south by Dodoma Region, to the southwest by Hanang District, and to the northwest by Mbulu district.

\section{Geographical and climatic information}

Babati district is located below the Equator between latitude $3^{\circ}$ and $4^{\circ}$ South and longitude $35^{\circ}$ and $36^{\circ}$ East. It has two periods of rain, the low rainfall period, which lasts from October to December, and high rainfall period which begins in March and ends in May. The climate zones observed are tropical and temperate with the average temperature ranging between $17-27^{\circ} \mathrm{C}$.

\section{Main income resource and population}

About $90 \%$ of the population of Babati District live in the rural areas and depend on agriculture and livestock for their livelihood. Mixed crop-livestock, mostly maizebased system are widely found in the district that are intercropped with varying species, such as common beans, pigeon peas and sunflowers, depending on altitude and availability of rainfall.

According to the national census of 2012, the district has a population of 312,392 people. Only $44 \%$ of the 96 villages have health facilities, such as dispensaries or health centers, whereas other villages are covered by the mobile and outreach services, especially for mother and childcare.

\section{Monduli district}

Monduli District is one of the five districts of the Arusha Region of Tanzania. It is located in the northeastern section of the country. It is bordered to the north by Kenya, to the east by the Kilimanjaro Region and Arumeru District, to the south by the Manyara Region and to the west by Ngorongoro District and Karatu District. The town of Monduli is the administrative seat of the district. According to the Tanzania National Census of 2012, the population of Monduli District is 158,929 people and the 
total area of the district is $14,201 \mathrm{~km}^{2}$. The rainfall ranges from $500 \mathrm{~mm}$ to $1000 \mathrm{~mm}$ per year. The district possesses rich wildlife resources that give a potential for tourism activities and acts as a source of income for the country. The people that reside in the Monduli District are the Maasai people, known to be nomads who practice sheepherding as their occupation. The major economic activities are crop production and livestock keeping, however, livestock keeping is more dominant. Monduli District has one hospital, one health centre, and 22 dispensaries.

In parallel with a study of seroprevalence of sparganosis among inhabitants of the two districts (Babati and Monduli); This study was conducted to determine the seroprevalence of Schistosomia mansoni, Echinococcus multilocularis and Toxoplasma gondii antibodies among the inhabitants of the two districts (Babati aand Monduli) in Northern Tanzania for which the prevalence of these diseases has not been reported before in these districts.

A cross-sectional study was carried out among inhabitants in Babati and Monduli districts. The villages which are saved by the health facility were randomly selected. The participants were randomly selected from outpatient in the health center and were grouped according to the villages they belonged to and only one participant was selected from each household to participate in the study. Approximately $4 \mathrm{ml}$ of venous blood was collected from each participant using vacutainers and the serum was pipetted into cryogenic vials which was then stored at $-20^{\circ} \mathrm{C}$. A total of 345 blood samples were collected from 160 and 185 randomly selected households from Babati and Monduli districts, respectively, from three different wards in each of the districts between February and May of 2012 (Table 1).

The ethical approval to use these samples specifically for this entire study was obtained from the National Institute for Medical Research (NIMR), an institution under the Ministry of Health and Social Welfare, Tanzania. It is the sole institution in the country, responsible for ethical approval of all research involving human and human material. The National Institute for Medical Research gave ethical approval (Ref: NIMR/HQ/ R.8a/VOL.IX/1285) for serological studies on Spirometra (unpublished data) and co-infections with echinococcosis, schistosomiasis and toxoplasmosis, from the $4 \mathrm{ml}$ of blood taken from each volunteer. Respective health and government authorities at regional and district level received copies of the ethical approval as required for the implementation of the study. At the individual level, a written consent was sought after detailed explanation of the purpose and the benefits of the study. Participants were informed that their participation was totally voluntary and that they were free to participate or not to participate to the study without giving any reason whatsoever. Written and signed or thumb-printed
Table 1 General characteristics of the participants from Monduli and Babati districts, Tanzania $(\mathbf{n}=\mathbf{3 4 5})$

\begin{tabular}{ll}
\hline Characteristics & N (\%) \\
Age group (years) & \\
\hline $1-15$ & $15(4.3)$ \\
$16-30$ & $128(37.1)$ \\
$31-45$ & $99(28.7)$ \\
$46-60$ & $75(21.7)$ \\
$61-75$ & $23(6.7)$ \\
$76-90$ & $4(1.2)$ \\
$>91$ & $1(0.3)$ \\
Gender & \\
Male & $136(39.4)$ \\
Female & $209(60.6)$ \\
District & \\
Babati & $160(46.4)$ \\
Monduli & $185(53.6)$ \\
Ward & \\
Mamire & $47(13.6)$ \\
Galapo & $31(9.0)$ \\
Magugu & $82(23.8)$ \\
Mto wa mbu & $54(15.7)$ \\
Losirwa & $103(29.9)$ \\
Esilelia & $28(8.1)$ \\
\hline
\end{tabular}

consents were obtained from all participants before were involved in the study. In case of the minors or children involved in the study, the next of kin, carer or guardian on behalf signed or thumb-printed the consent form. The samples were sent to the Department of Parasitology, Department of Medicine, University of Malaya, Malaysia in April 2013.

\section{Serology}

The NovaLisa ${ }^{\circ}$ Toxoplasma gondii IgG, NovaLisa ${ }^{\circ}$ Schistosoma Mansoni IgG, NovaLisa ${ }^{\circ}$ Echinococcus IgG and NovaLisa ${ }^{\circ}$ Toxoplasma gondii IgM kits (Novatec, Germany) were used in this study. The sensitivity of the respective kits is as follows: $96.6 \%, 87 \%, 95 \%$ and $95.8 \%$ whereas the specificity of aforementioned kits is $98.2 \%$, 95\%, 95\% and 98\%. The analysis was performed in Department of Parasitology, University of Malaya. Statistical analysis was performed using SPSS v.20 (SPSS IBM, New York, U.S.A). A Pearson's Chi-square $\left(\chi^{2}\right)$ test was used to test the association between categorical variables and Post -Hoc analysis was performed on statistically significant variables to explore the association between the variables of interest. Odd ratios (ORs), relative risk (RR) and 95\% confidence interval (95\% CI) were calculated, furthermore, logistic regression was 
used to identify the significant predictors and to control the potential confounding effect. A. The level of statistical significance was set at $\mathrm{p}<0.05$ for each test. Prior to analyzing, the data was stratified according to districts (Babati, Monduli), wards (Mamire, Galapo, Magugu, Mtowambu, Losirwa, Esilelia), gender (male/female) and age group (1-15, 16-30, 31-45, 46-60, 61-75, 76-90, >91) in years.

\section{Results}

The general characteristics of participants according to age, gender, district and divisions are shown in Table 1.

\section{Seroprevalence of echinococcosis}

Among the 345 serum samples tested, 39 (11.3\%, 95\% $\mathrm{CI}=7.96-14.6)$ were positive for Echinococcus multilocularis antibodies. Univariate analysis was performed to check the association of positive results with gender, age group and district (Table 2). There was no statistically significant association detected with either one of the variables being tested. However, association tested among the wards of both districts (Table 3) showed that there was a significant difference between the wards of Babati district ( $\mathrm{p}$ value $<0.01$ ). Post-hoc analysis showed that there is a significant difference between Mamire and Gelapo ( $\mathrm{p}=0.01,95 \% \mathrm{CI} 0.101-0.473$ ) as well as Mamire and Magugu ( $\mathrm{p}=0.03,95 \% \mathrm{CI}=0.0774-0.439$ ). Logistic regression analysis could not detect any significant association between echinococcosis- positive IgG and the examined variables (Table 4). The chi-square results for the distribution of positive IgG and IgM (only $T$. gondii) results according to age groups are shown in Table 5.

\section{Seroprevalence of schistosomiasis}

ELISA results showed 177 (51.3\%, 95\% CI =46.0-56.5) positive samples out of 345 serum samples for Schistosoma mansoni antibodies. Statistical analysis (Table 2) demonstrated that a significantly higher prevalence of schistosomiasis in Monduli as compared to Babati ( $R R=1.40$, 95\% CI $=1.13-1.74)$. Univariate tests between the wards of Monduli (Table 3) revealed that there is a significant difference in the prevalence of schistosomiasis between the divisions $(p=0.03)$. Post-Hoc analysis showed significant difference among two of the divisions, Losirwa and Mto Wa Mbu ( $\mathrm{p}=0.004,95 \% \mathrm{CI}=0.0714-0.486)$. Binary logistic regression also yielded the same pattern of results for districts $(\mathrm{OR}=1.94,95 \% \mathrm{CI}=1.23-3.08)$ and for the other two variables (Table 4).

\section{Seroprevalence of toxoplasmosis}

Out of the 345 serum samples, 199 (57.68\%, 95\% CI =52.562.9) were positive for Toxoplasma gondii IgG antibodies. A Pearson's Chi-square $\left(x^{2}\right)$ test (Table 2) showed a statistical significant difference between the occurrence of infection among the two districts $(\mathrm{RR}=1.57,95 \% \mathrm{CI}=1.22$ 2.01). Multivariate analysis also indicated that district was

Table 2 Univariate analysis for the association between risk factors and seroprevalence

\begin{tabular}{|c|c|c|c|c|}
\hline Risk factor & Echinococcosis & Schistosomiasis & Toxoplasmosis IgG & Toxoplasmosis IgM \\
\hline & N/Total (\%) & & & \\
\hline \multicolumn{5}{|l|}{ Gender } \\
\hline Male & 19/136 (13.9) & 65/136 (47.8) & $71 / 136$ (52.2) & $17 / 136(12.5)$ \\
\hline Female & 20/209 (9.56) & 112/209 (53.6) & 128/209 (61.2) & $22 / 209(10.5)$ \\
\hline RR & 1.46 & 0.892 & 0.852 & 1.19 \\
\hline$(95 \% \mathrm{Cl})$ & $(0.810-2.633)$ & $(0.718-1.107)$ & $(0.702-1.035)$ & $(0.655-2.153)$ \\
\hline P-value & 0.207 & 0.293 & 0.097 & 0.572 \\
\hline \multicolumn{5}{|l|}{ District } \\
\hline Babati & 18/185 (9.73) & 109/185 (58.9) & $123 / 185$ (66.5) & 16/185 (8.65) \\
\hline Monduli & $21 / 160(13.1)$ & $68 / 160(42.5)$ & $76 / 160$ (47.5) & 23/160 (14.4) \\
\hline RR & 0.962 & 1.400 & 1.567 & 0.937 \\
\hline$(95 \% \mathrm{Cl})$ & $(0.891-1.04)$ & $(1.13-1.74)$ & $(1.22-2.01)$ & $(0.867-1.01)$ \\
\hline P-value & 0.321 & 0.002 & 0.000 & 0.094 \\
\hline \multicolumn{5}{|l|}{ Age group } \\
\hline$\leq 60$ & 35/317 (11.0) & $164 / 317(51.7)$ & 187/317 (59.0) & $36 / 317(11.3)$ \\
\hline$>60$ & $4 / 28(13.3)$ & $13 / 28(46.4)$ & $12 / 28(42.8)$ & $3 / 28(10.7)$ \\
\hline RR & 0.773 & 1.114 & 1.376 & 1.060 \\
\hline$(95 \% \mathrm{Cl})$ & $(0.296-2.02)$ & $(0.738-1.68)$ & $(0.889-2.13)$ & $(0.348-3.23)$ \\
\hline P-value & 0.603 & 0.590 & 0.098 & 0.918 \\
\hline
\end{tabular}


Table 3 Univariate analysis for the association between the divisions of districts and seroprevalence

\begin{tabular}{lllll}
\hline Location & Echinococcosis & Schistosomiasis & Toxoplasmosis IgG & Toxoplasmosis IgM \\
\hline Babati wards & $\mathbf{N} /$ Total (\%) & & & \\
Mamire & & & & \\
Galapo & $15 / 47(31.9)$ & $26 / 47(55.31)$ & $22 / 47(46.8)$ & $8 / 47(17.0)$ \\
Magugu & $1 / 31(3.22)$ & $12 / 31(38.7)$ & $10 / 31(32.2)$ & $6 / 31(19.3)$ \\
P-value & $5 / 82(6.09)$ & $30 / 82(36.5)$ & $44 / 82(53.6)$ & $9 / 82(10.9)$ \\
Monduli wards & 0.000 & 0.106 & 0.127 & 0.441 \\
Mto wa Mbu & $7 / 54(12.9)$ & & & $2 / 54(3.70)$ \\
Losirwa & $10 / 102(9.80)$ & $23 / 54(42.6)$ & $37 / 54(68.5)$ & $10 / 102(9.80)$ \\
Esilelia & $1 / 29(3.44)$ & $71 / 102(69.6)$ & $62 / 102(60.8)$ & $4 / 29(13.8)$ \\
P-value & 0.382 & $15 / 29(51.7)$ & $24 / 29(82.7)$ & 0.248 \\
\hline
\end{tabular}

the most important factor, with the samples from Monduli having higher seropositivity $(\mathrm{OR}=2.09,95 \% \mathrm{CI}=1.31-3.32)$. As for T. gondii IgM, only 39(11.3\%, 95\% CI =7.96-14.6) serum samples were positive. Univariate (Table 2) and multivariate analysis (Table 4) did not give any statistically significant results for any of the variables being tested.

\section{Discussion}

The antibody detection methods are not $100 \%$ specific and sensitive, thus the findings of this study should be interpreted with caution. Furthermore, the specificity and sensitivity of the detection methods depend on the antigen used when performing ELISA. The use of clinical diagnosis for positive cases would have elucidated even more information regarding the prevalence of these infectious diseases. However, this could not be accomplished in this study due to lack of manpower and the required expertise in the sampling site to carry out clinical test. Despite this, the pattern observed helps to access the prevalence in a population.

We detected $11.5 \%$ (8.00 - 14.6) seroprevalence among the samples tested. The antigens used cannot differentiate between $E$. granulosa and $E$. multilocularis antibodies. However, because alveolar echinococcosis is prevalent in the Northern hemisphere and cystic echinococcosis is endemic in Sub-Saharan Africa [7], E. granulosa could be responsible for the seroprevalence detected but this should be confirmed with clinical tests. Our result reveals a far greater infection rate than the $0.007 \%$ reported in Burkina Faso [27], 0.3 - 0.8\% in central Sudan [28], and the $2 \%$ and $3.5 \%$ among Bouya and Topasa populations, respectively, in southern Sudan [29]. The only two countries that are well researched are Kenya and Sudan. In Nigeria, sonar scan results depicted a prevalence of 5.1\% [30]. The IgG antibodies can be detected in patients that are currently in the asymptomatic phase [31], which could be the reason for the high

Table 4 Multivariate analysis for the association between risk factors and seroprevalence

\begin{tabular}{|c|c|c|c|c|}
\hline Risk factor & Echinococcosis & Schistosomiasis & Toxoplasmosis IgG & Toxoplasmosis IgM \\
\hline & Adjusted OR (95\% & & & \\
\hline \multicolumn{5}{|l|}{ Gender } \\
\hline Male/Female & $1.40(0.673-2.927)$ & $1.01(0.627-1.639)$ & $0.958(0.589-1.557)$ & $1.02(0.487-2.122)$ \\
\hline P-value & 0.365 & 0.957 & 0.861 & 0.966 \\
\hline \multicolumn{5}{|l|}{ District } \\
\hline Babati/Monduli & $0.811(0.395-1.662)$ & $1.94(1.227-3.078)$ & $2.09(1.310-3.326)$ & $0.557(0.271-1.148)$ \\
\hline P-value & 0.567 & 0.005 & 0.002 & 0.113 \\
\hline \multicolumn{5}{|l|}{ Age } \\
\hline$\leq 60 />60$ & $0.915(0.287-2.910)$ & $1.04(0.462-2.346)$ & $1.56(0.689-3.551)$ & $1.25(0.345-4.543)$ \\
\hline P-value & 0.880 & 0.923 & 0.285 & 0.732 \\
\hline
\end{tabular}


Table 5 Chi-square for age groups

\begin{tabular}{llllll}
\hline Age groups (years) & $\mathbf{N}(\%)$ & Echinococcosis & Schistosomiasis & Toxoplasmosis IgG & Toxoplasmosis IgM \\
\hline $1-10$ & $9(2.6)$ & $1(0.3)$ & $4(1.2)$ & $8(2.3)$ & $0(0.0)$ \\
$11-20$ & $54(15.7)$ & $1(0.3)$ & $32(9.3)$ & $35(10.1)$ & $6(1.7)$ \\
$21-30$ & $80(23.2)$ & $10(2.9)$ & $45(13.0)$ & $48(13.9)$ & $9(2.6)$ \\
$31-40$ & $70(20.3)$ & $9(2.6)$ & $33(9.6)$ & $39(11.3)$ & $6(1.7)$ \\
$41-50$ & $63(18.3)$ & $10(2.9)$ & $32(9.3)$ & $37(10.7)$ & $8(2.3)$ \\
$51-60$ & $41(11.9)$ & $4(1.2)$ & $18(5.2)$ & $20(5.8)$ & $7(2.0)$ \\
$>60$ & $28(8.1)$ & $4(1.2)$ & $13(3.8)$ & $12(3.5)$ & $3(0.9)$ \\
Total (\%) & $345(100)$ & $39(11.3)$ & $177(51.3)$ & $199(57.7)$ & $39(11.3)$ \\
$X^{2}$ & & 6.75 & 3.98 & 8.88 & 3.16 \\
P-value & & 0.344 & 0.680 & 0.180 & 0.788 \\
\hline
\end{tabular}

seroprevalence observed in this study. Additionally, specificity issues in the enzyme linked immunosorbent assay (ELISA) can lead to cross-reactions with other species of Echinococcus or with cysticercosis and give false positive results [1]. Finally, IgG antibody production is dependent on many factors such as size, number, surface antigen orientation, and the condition of the hydatid cysts [2]. No antibody production has been observed due to the presence of small cysts, intact cysts, or calcified cysts [32].

The incidence of cystic echinococcosis is not uniformly distributed in Sub-Saharan Africa. Overall, rates of infection are higher in the arid regions of Sahel and in eastern and southern Africa where the household income primarily depends on livestock husbandry. Rates of infection are less frequent in areas with adequate rainfall in western and central Africa where livestock is limited [7]. The difference in infection rates could be due to the fact that the governing bodies place low importance on the dry pastoral areas because they contribute little to the gross domestic product. Sub-Saharan Africa is at the bottom of the list in terms of contribution to world economics, therefore, the majority of the area is underdeveloped, and rural areas are a significant risk factor for cystic echinococcosis [2,33]. Age can be another risk factor [33,34], but in the present study age did not have a significant effect. Another risk factor for echinococossis is a high prevalence of hydatidosis in livestock and not de-worming the animals [35]. One of the main occupations in Babati and Monduli is livestock keeping, which may also increase their risk of disease $[36,37]$. We observed a significant difference in the seroprevalence among the Babati wards which could be due to unhygienic conditions, genetic predisposition, malnutrition-related immunosuppression [38], close contact with dogs, and a high number of infected livestock.

Schistosoma haemotobium and S. mansoni cause urogenital schistosomiasis and intestinal schistosomiasis, respectively, and in Africa they contribute more to mortality rate than other species [39]. Globally, the prevalence of these parasites tends to increase due to man-made lakes, construction of dams, and irrigation projects. Civil wars also increase prevalence, because they are one of the primary reasons for migration [39,40]. Tanzania has the second highest prevalence of schistosomiasis in Africa, coming just behind Nigeria $[39,41]$. The water supply projects initiated in the late 1970's have been blamed for the transmission of the parasite because they provide a suitable habitat for the intermediate host, snails, which promote the spread of disease [42-46]. Schistosoma mansoni are rarely present in the coastal regions because of thermal exclusion and because there is no intermediate host [47]. The potential host candidates for S. mansoni are Biomphalaria choanomphala, B. pfeifferi, B. sudanica, and B. angulosa [39,48]. Biompharlaria choanomphala is confined to large bodies of water and hydro-electrical dams in the south and east-south of the country, whereas B. sudanica is found in dams, on the southern shores of Lake Victoria, and in the north [42]. Biomphalaria pfeifferi is widely distributed in seasonal water sources and swamps throughout the majority of Africa, whereas B. angulosa is primarily observed in swamps only in the southern highlands $[39,47,49]$. In 2012, the prevalence of schistosomiasis was estimated to be $51.5 \%$ [50]. The present study confirms this estimate (51.3\%). A large number of intermediate hosts may explain the high seroprevalence observed in this study.

In S. mansoni endemic places, once the immigrants are exposed to the parasite, they also tend to show the same age-pattern as of the residents in terms of infection [51]. Children under 15 years old are the most prone to S. mansoni infection, but it does affect people of all age groups $[47,48]$. The high infection rate in children under 15 could be due to a more frequent contact with water, or it could be due to the development of immunity in adults that lowers prevalence in older populations [52]. However, our results can be explained by high occupational contact or the use of contaminated water for household work [53]. We observed a significant difference between the districts and between the Monduli 
wards (Mto wa Mbu and Losirwa), which suggests that there is a significantly higher infection rate in the Monduli district compared to Babati. In regards to the wards, our results reveal a higher seroprevalence in the Losirwa ward than in Mto wa Mbu. Several socio-epidemiological factors such as population movement, distance from origin of disease, urbanization, employment status, cleanliness, and the level of fecal contamination in the water supply could explain the high transmission of schistosomiasis in these areas. There is also an increased susceptibility to infection if one handles snails or practices fishing, farming, bathing, and swimming in contaminated water bodies.

Over the course of a T. gondii infection, IgM antibodies are typically the first class of antibodies present in primary response, and they also subside more quickly than IgG antibodies [54]. The most common serological marker to diagnose a recently acquired infection is to measure the specific IgM antibodies [55]. In this study, the seroprevalence of T. gondii IgM antibodies was $11.3 \%$, which demonstrates that most infections are not acute, and thus the IgM antibody titer is too low to be detected. Another way to distinguish between an acute and a past infection is by using the IgG avidity test. The most convenient and widely used methods to diagnose $T$. gondii infection is by measuring the IgG antibodies through SabinFeldman dye test, ELISA, Indirect immunofluorescent assay (IFA) and the modified direct agglutination test [56].

The seroprevalence of $T$. gondii IgG antibodies in this study demonstrate that the residents of Monduli and Babati experience a high exposure to T. gondii. Our study found $57.7 \%$ prevalence of $T$. gondii, which is higher than a study carried out in the Tanga district that reported a seroprevalence of $45.7 \%$ [22]. Other Tanzanian studies report 35.0\% prevalence in Dar es Salaam [57], and a high seroprevalence of $72.2 \%$ was reported among the Hadzabe in the northern region of the country [58]. The seroprevalences reported by the present study are similar to several studies performed on exposed groups in Africa. For example, seroprevalences of $52.4 \%$ and $42.6 \%$ were reported among slaughterhouse workers in Egypt and Djibout, respectively $[59,60]$. Similarly, studies in Congo yielded $41.9 \%$ seroprevalence in cattle breeders and slaughterhouse employees [61], whereas in Gezira Province, Sudan, $41.7 \%$ of pregnant women were seropositive [62].

Our findings did not concur with patterns of reduced seroprevalence among older populations that had been observed in studies carried out in Nigeria and Congo $[61,63]$. This trend was not observed in this study, which could be due behavioral differences in the societies. We found no statistical difference in seroprevalence between males and females (Table 2), however other studies have suggested that gender does influence exposure or immune response towards $T$. gondii $[61,64]$. The lack of difference in the antibody count between the two genders in our study could be due to similar everyday activities in which the individual is exposed to the parasite, which as a result does not make one gender more prone to the parasite that the other. We observed a difference in seroprevalence between the Monduli and Babati districts, which implies that factors that influence the high infection rate in Monduli are not present in the Babati district. These factors may include consumption of contaminated water, fruits, and undercooked meat [65-67]. Eating raw and undercooked meat is still practiced in some areas of Tanzania [68].

\section{Conclusion}

The lack of sufficient information regarding zoonotic disease could be a result of ineffective public education and a lack of communication between veterinary and human health professionals. Insufficient information prevents the people from taking precautionary measures, which in turn lead to an increased risk of infection. In future studies, the surveys used should have more depth to gain information regarding the socioeconomic status of the individuals being used in the study. Our findings show that there is a higher percentage of S. mansoni and T. gondii infections in the Monduli district as compared to the Babati district. In terms of the wards of the Monduli district, Losirwa has a higher risk of infection to the S. mansoni parasite as opposed to the Mto Wa Mbu ward. This suggests that there is a pressing need to improve education about the risk factors and prevention methods, especially in the Monduli district, which could result in a significant reduction in disease transmission.

\section{Competing interests}

The authors declare that they have no competing interests.

\section{Authors' contributions}

RM, YLL, AK and CK conceived and designed the study. MBK, PS and NK performed the experiments. MBK, YLL and HMA analysed the data, drafted the manuscript and helped in manuscript revision. All authors read and approved the final manuscript.

\section{Acknowledgement}

We wish to thank the participants who donated their blood for this study. This study was funded by University of Malaya High Impact Research Fund UM-MOHE (UM.C/625/1/HIR/MOHE/CHAN/14/3 and UM.C/HIR/MOHE/MED/ 16) from the Ministry of Higher Education, Malaysia

\section{Author details}

${ }^{1}$ Department of Parasitology, Faculty of Medicine, University of Malaya, Kuala Lumpur, Malaysia. ${ }^{2}$ Department of Veterinary Microbiology and Parasitology, Faculty of Veterinary Medicine, Sokoine University of Agriculture, Morogoro, Tanzania.

Received: 21 July 2014 Accepted: 28 October 2014

Published online: 12 November 2014

\section{References}

1. Craig PS, McManus DP, Lightowlers MW, Chabalgoity JA, Garcia HH: Prevention and control of cystic echinococcosis. Lancet Infect Dis 2007, 7:385-394.

2. Moro P, Schantz PM: Echinococcosis: a review. Int J Infect Dis 2009, 13:125-133.

3. Handa U, Bal A, Mohan H: Cytomorphology of hydatid cyst. Internet J Trop Med 2004, 2:6 
4. McManus D, Zhang W, Bartley P: Echinococcosis. Lancet 2003, 362:1295-1304.

5. Budke CM, Deplazes P, Torgerson PR: Global socioeconomic impact of cystic echinococcosis. Emerg Infect Dis 2006, 12:296-303.

6. Jenkins DJ, Romig T, Thompson RCA: Emergence/re-emergence of echinococcus spp.- a global update. Int J Parasitol 2005, 35:1205-1219.

7. Magambo J, Njoroge E, Zeyhle E: Epidemiology and control of echinococcosis in sub-Saharan Africa. Parasitol Int 2006, 55:S193-S195.

8. Eckert J, Deplazes P: Biological, epidemiological, and clinical aspects of echinococcosis, a zoonosis of increasing concern. Clin Microbiol Rev 2004, 17:107-135.

9. WHO: The social context of schistosomiasis and its control. Geneva, Switzerland: World Health Organization; 2008.

10. Hotez PJ, Kamath A: Neglected tropical diseases in sub-saharan Africa: review of their prevalence, distribution, and disease burden. PLOS Negl Trop Dis 2009, 3:e412.

11. Hotez PJ: Mass drug administration and integrated control for the world's high-prevalence neglected tropical diseases. Clin Pharmacol Ther 2009, 85:659-664.

12. Bahia-Oliveira LM, Jones JL, Azevedo-Silva J, Alves CC, Orefice F: Highly endemic, waterborne toxoplasmosis in north Rio de Janeiro state, Brazil. Emerg Infect Dis 2003, 9:55-62.

13. Dubey JP: Toxoplasmosis - a waterborne zoonosis. Vet Parasito/ 2004 126:57-72.

14. Jones JL, Lopez B, Alvarez Mury M, Wilson M, Klein R: Toxoplasma gondii infection in rural Guatemalan children. Am J Trop Med Hyg 2005, 72:295-300

15. De Moura L, Bahia-Oliveira LMG, Wada MY, Jones JL, Tuboi SH: Waterborne toxoplasmosis, Brazil, from field to gene. Emerg Infect Dis 2006, 12:326-329.

16. Rosenberg C, De Craeye S, Jongert E, Gargano N, Beghetto E: Induction of partial protection against infection with Toxoplasma gondii genotype II by DNA vaccination with recombinant chimeric tachyzoite antigens. Vaccine 2009, 27:2489-2498.

17. Su C, Shwab EK, Zhou P, Zhu XQ, Dubey JP: Moving towards an integrated approach to molecular detection and identification of Toxoplasma gondii. Parasitology 2010, 137:1-11.

18. Prandota J: The importance of toxoplasma gondii infection in diseases presenting with headaches. Headaches and aseptic meningitis may be manifestations of the Jarisch-Herxheimer reaction. Int J Dev Neurosci 2009, 119:2144-2182

19. Shin DW, Cha DY, Hua QJ, Cha GH, Lee YH: Seroprevalence of Toxoplasma gondii infection and characteristics of seropositive patients in general hospitals in Daejeon, Korea. Korean J Parasitol 2009, 47:125-130.

20. Xiao Y, Yin J, Jiang N, Xiang M, Hao L: Seroepidemiology of human Toxoplasma gondii infection in China. BMC Infect Dis 2010, 10:4.

21. Kamani J, Mani AU, Egwu GO, Kumshe HA: Seroprevalence of human infection with Toxoplasma gondii and the associated risk factors, in Maiduguri, Borno state, Nigeria. Ann Trop Med Parasitol 2009, 103:317-321.

22. Swai ES, Schoonman L: Seroprevalence of Toxoplasma gondii infection amongst residents of Tanga district in north-east Tanzania. Tanzan $J$ Health Res 2009, 11:205-209.

23. Fromont EG, Riche B, Rabilloud M: Toxoplasma seroprevalence in a rural population in France: detection of a household effect. BMC Infect Dis 2009, 9:76.

24. Silveira $C$, Belfort $R \mathrm{Jr}$, Burnier M Jr, Nussenblatt R: Acquired toxoplasmic infection as the cause of toxoplasmic retinochoroiditis in families. Am $J$ Ophthalmol 1988, 106:362-364.

25. Doliwa C, Escotte-Binet S, Aubert D, Sauvage V, Velard F: Sulfadiazine resistance in Toxoplasma gondii: no involvement of overexpression or polymorphisms in genes of therapeutic targets and $A B C$ transporters. Parasite 2013, 20:19.

26. Innes EA: A brief history and overview of Toxoplasma gondii. Zoonoses Public Health 2010, 57:1-7.

27. Coulibaly ND, Yameogo KR: Prevalence and control of zoonotic diseases: collaboration between public health workers and veterinarians in Burkina Faso. Acta Tropica 2000, 76:53-57.

28. Elmahdi IE, Ali QM, Magzoub MM, Ibrahim AM, Saad MB: Cystic echinococcosis of livestock and humans in central Sudan. Ann Trop Med Parasitol 2004, 98:473-479.

29. Magambo J, Hall C, Zeyle E, Wachira TM: Prevalence of human hydatid disease in southern Sudan. Afr J Health Sci 1996, 3:154-156.
30. Magaji AA, Bello OS, Oboegbulem SI, Garba HS, Daneji Al: Research impediments in echinococcosis/hydatidosis in a resource poor country Nigeria. Int Arch Hydatid 2004, 35:76.

31. ECDC: Annual epidemiological report on communicable diseases in Europe. Stockholm, Sweden: European Centre of Disease Prevention and Control; 2010.

32. Gavidia CM, Gonzalez AE, Zhang W, McManus DP, Lopera L: Diagnosis of cystic echinococcosis, central Peruvian Highlands. Emerg Infect Dis 2008, 14:260-266.

33. Fotiou V, Malissiova E, Minas A, Petinaki E, Hadjichristodoulou C: Seroprevalence of IgG antibodies against Echinococcus granulosus in the population of the region of Thessaly. Central Greece. PLoS One 2012, 7:e37112.

34. Gutie'rrez M, Ramı'rez I, Zarzosa M, Ferna'ndez J, Duenas A: Seroprevalence of infection due to Echinococcus granulosus in the population of Castilla and Leo'n (Spain). Enferm Infecc Microbiol Clin 2003, 21:563-567.

35. Ernest E, Nonga HE, Kassuku AA, Kazwala RR: Hydatidosis of slaughtered animals in Ngorongoro district of Arusha region, Tanzania. Trop Anim Health Prod 2009, 41:1179-1185.

36. WVP: Village Reports for Mandi, Gidas, Boay, Mwada, Sangaiwe, and Vilima Vitatu in Babati District. Minnesota, USA: The Whole Village Project; 2010.

37. WVP: Village Reports for Engaruka, Migombani, Naitolia, and Selela in Monduli District. Minnesota, USA: The Whole Village Project; 2010.

38. Vuitton DA, Godot V, Zhang S, Harraga S, Penfornis A, Beurton I: Host immunogenetics and role in epidemiology of larval cestodoses. Nato Sci Ser / Life 2002, 341:83-194.

39. Steinmann P, Keiser J, Bos R, Tanner M, Utzinger J: Schistosomiasis and water resources development: systematic review, meta-analysis, and estimates of people at risk. Lancet Infect Dis 2006, 6:411-425.

40. Gryseels B, Polman K, Clerinx J, Kestens L: Human schistosomiasis. Lancet 2006, 368:1106-1118.

41. Ross AGP, Bartley PB, Sleigh AC, Olds GR, Li YS: Current concepts schistosomiasis. New Engl J Med 2002, 346:1212-1220.

42. Eltawil KM, Plassmann M: Theodor Bilharz (1825-1862): discoverer of schistosomiasis. Int J Parasitol Res 2011, 3:17-25.

43. Brown M, Mawa PA, Kaleebu P, Elliott AM: Helminths and HIV infection: epidemiological observations on immunological hypotheses. Parasite Immunol 2006, 28:613-623.

44. Secor WE: Interactions between schistosomiasis and infection with HIV-1. Parasite Immunol 2006, 28:597-603.

45. Nokta MA, Li XD, Nichols J, Mallen M, Pou A: Chemokine/CD4 receptor density ratios correlate with HIV replication in lymph node and peripheral blood of HIV-infected individuals. Aids 2001, 15:161-169.

46. Kamal SM, Bianchi L, Al Tawil A, Koziel M, Khalifa KE: Specific cellular immune response and cytokine patterns in patients coinfected with hepatitis C virus and Schistosoma mansoni. J Infect Dis 2001, 184:972-982

47. Barakat R, Farghaly A, El Masry AG, El-Sayed MK, Hussein MH: The epidemiology of schistosomiasis in Egypt: patterns of schistosoma mansoni infection and morbidity in Kafr El-Sheikh. Am J Trop Med Hyg 2000, 62:21-27.

48. Boisier P, Serieye J, Ravaoalimalala VE, Roux J, Esterre P: Ultrasonographical assessment of morbidity in schistosomiasis mansoni in Madagascar: a community-based study in a rural population. Trans $R$ Soc Trop Med Hyg 1995, 89:208-212.

49. Cossarizza A, Ortolani C, Mussini C, Borghi V, Guaraldi G: Massive activation of immune cells with an intact T-cell repertoire in acute human-immunodeficiency-virus syndrome. J Infect Dis 1995, 172:105-112

50. Mazigo HD, Nuwaha F, Wilson S, Kinung'hi SM, Morona D: Epidemiology and interactions of human immunodeficiency virus - 1 and Schistosoma mansoni in sub-Saharan Africa. Infect Dis Poverty 2013, 2:2

51. Ouma JH, Fulford AJ, Kariuki HC, Kimani G, Sturrock RF: The development of schistosoma mansoni in an immunologically naive immigrant population in Masongaleni. Kenya. Parasitology 1998, 117(Pt 2):123-132.

52. Savioli L, Dixon H, Kisumku UM, Mott KE: Control of morbidity due to schistosoma hematobium on Pemba-Island - program organization and management. Trop Med Parasitol 1989, 40:189-194.

53. Savioli L, Mott KE: Urinary schistosomiasis on Pemba Island - low-cost diagnosis for control in a primary health-care setting. Parasitol Today 1989, 5:333-337.

54. Montoya JG: Laboratory diagnosis of toxoplasma gondii infection and toxoplasmosis. J Infect Dis 2002, 185:S73-S82. 
55. Suzuki LA, Rocha RJ, Rossi CL: Evaluation of serological markers for the immunodiagnosis of acute acquired toxoplasmosis. Int J Med Microbiol 2001, 50:62-7066.

56. Hill D, Dubey JP: Toxoplasma gondii: transmission, diagnosis and prevention. Clin Microbiol Infec 2002, 8:634-640.

57. Doehring E, Reiterowona I, Bauer O, Kaisi M, Hlobil H: Toxoplasma gondi antibodies in pregnant-women and their newborns in Dar-Es-Salaam, Tanzania. Am J Trop Med Hyg 1995, 52:546-548.

58. Bennett FJ, Kagan IG, Barnicot NA, Woodburn JC: Helminth and protozoal parasites of the Hadza of Tanzania. Trans R Soc Trop Med Hyg 1970, 64:857-880.

59. Chantal J, Bessiere MH, LeGuenno B, Magnaval JF, Dorchies P: A sero-prevalence survey of carriers of the agents of zoonotic diseases on some workers of Djibouti slaughter-house. B Soc Pathol Exot 1996, 89:353-357.

60. Ibrahim BB, Salama MMI, Gawish NI, Haridy FM: Serological and histopathological studies on toxoplasma gondii among the workers and the slaughtered animals in Tanta Abattoir, Gharbia Governate. J Egyp Soc Parasitol 1997, 27:273-278,

61. Candolfi E, Berg M, Kien T: Prevalence of toxoplasmosis in Pointe-Noire in Congo. Study of the sampling of 310 subjects. Bull Soc Pathol Exot 1993, $86: 358-362$

62. Abdel-Hameed AA: Sero-epidemiology of toxoplasmosis in Gezira, Sudan. J Trop Med Hyg 1991, 94:329-332.

63. Osiyemi TIO, Synge EMM, Agbonlahor DE, Agbavwe R: The prevalence of toxoplasma gondii antibodies in man in Plateau state and meat animals in Nigeria. Trans R Soc Trop Med Hyg 1985, 79:21-23.

64. Uneke CJ, Duhlinska DD, Ngwu BA, Njoku MO: Seroprevalence of toxoplasma gondii infection in Kwal, a rural distriction of Plateau-Nigeria. Afr J Med Med Sci 2007, 36:109-113.

65. Alvarado-Esquivel C, Estrada-Martinez S, Liesenfeld O: Toxoplasma gondii infection in workers occupationally exposed to unwashed raw fruits and vegetables: a case control seroprevalence study. Parasit Vectors 2011, 4:235

66. Ertug S, Okyay P, Turkmen M, Yuksel H: Seroprevalence and risk factors for toxoplasma infection among pregnant women in Aydin province. Turkey. Bmc Public Health 2005, 5:66.

67. Bowie WR, King AS, Werker DH, IsaacRenton JL, Bell A: Outbreak of toxoplasmosis associated with municipal drinking water. Lancet 1997, 350:173-177.

68. Shirima GM, Fitzpatrick J, Cleaveland S, Kambarage DM, Kazwala RR: Participatory survey on zoonotic diseases affecting livestock keeping communities in Tanzania. J Anim Vet Adv 2003, 2:253-258.

doi:10.1186/s13071-014-0505-7

Cite this article as: Khan et al:: High seroprevalence of echinococossis, schistosomiasis and toxoplasmosis among the populations in Babati and Monduli districts, Tanzania. Parasites \& Vectors 2014 7:505.

\section{Submit your next manuscript to BioMed Central and take full advantage of:}

- Convenient online submission

- Thorough peer review

- No space constraints or color figure charges

- Immediate publication on acceptance

- Inclusion in PubMed, CAS, Scopus and Google Scholar

- Research which is freely available for redistribution 